\title{
INFORMATION SYSTEMS AND CORPORATE MEMORY: DESIGN FOR STAFF TURN-OVER ${ }^{2}$
}

\author{
Colin A. Sharp \& Neil R. Lewis \\ School of Accounting Finance and Management \\ Flinders University, South Australia
}

\begin{abstract}
The "information age" is reliant upon the information skill-base of people and the storage and access of complete data. Staff tum-over and "down-sizing" as well as the rate of organisational change places increased pressure on the designers of corporate information systems to keep up with the organizational demands. Especially relevant are the "soft", aspects of the corporate information needs of organizations. The term "corporate memory" is introduced to explain the relatively informal collective and individual knowledge of employees gained through their experience and position in the organization. This paper elaborates the issues concemed with the "corporate soft data", and makes suggestions for research, as well as for planners of corporate information systems in organizations facing major down-sizing or related changes. It is concluded that there are a number of readily obtainable sources of soft data in the organization and these data should be analysed for inclusion in system development. If organizations are to become leaming systems and not just keep repeating the same mistakes, they need to review all aspects of corporate memory, especially the soft data sources and losses.
\end{abstract}

\section{INTRODUCTION}

Staff turn-over, and "right-sizing" of organizations are commonplace in the public sector and private sector bureaucracies in economic down-turns. For example, the CEO of Eastman Kodak told the World Management Congress in one strategic change he had to "down-size" 15,000 of his employees from the Company town, Rochester, New York (Samper, 1989). In Australia almost 200,000 (or about 1 in every 8) jobs have been lost in the first two years of the current recession with a further wave of "down-sizing" occurring currently.

This painful trend has been the subject of research by psychologists, concerned with "survivor sickness" (Marks \& Mirvis, 1992), i.e., the stressful effects on employees of the uncertainty of change, as well as the anxiety of unemployment for those retrenched (e.g., Cartwright \& Cooper, $1990,1993)$ and the focus of management researchers concemed with the associated problems of productivity and organization effectiveness (Cartwright \& Cooper, 1990; Hunt, 1988).

Increasingly, the consequences of continual organizational change are becoming a matter for concern of information system managers. The computing and information systems are expected to substitute for personnel more than ever. Information Systems Managers increasingly have to deal with the difficulties of qualitative information storage in these circumstances.

This paper provides a review of some of the experiences of public sector organizations which have undergone major organizational changes, and some of the key issues concerning design of information storage in anticipation of such changes. The findings of the review suggest implications for design and implementation of preventative approaches.

\section{The Organisational Problems to be Addressed}

In Australia, the economic down-turn and government policies have led to the redundancy, retrenchment or redeployment of thousands of personnel from the public and private sectors. Public sector "reforms" and cut-backs in State and Commonwealth bureaucracies have led to many retrenchments from the public sector. Indeed, according to a recent report from the Economic Planning Advisory Council (cited by Colebatch, 1993), 38 state and federal government business enterprises cut about 50,000 jobs in two years. These unemployed are not merely from the ranks of the lower levels of the public sector, but since the abolition of the Public Service Board in 1987, have included the ranks of the Senior Executive Service (Jacka, 1988). For example, according to the

2. An earlier version of this paper was presented to the Third Australian Conference on Information Systems at the University of Wollongong October 1992 . We thank the participants for their encouraging comments. 
former Director of the Senior Executive Service Unit, Harvey Jacka (1988, p. 45), "the recent machinery of government changes have had a significant impact on the SES". The re-structuring of government departments from August 1987, "displaced" at least 125 SES officers within the following three months. Even though the Commission was said to regard these "SES staff [as] a valuable resource" it was prepared to "cut the SES by 90 , that is, about 5 per cent." (Jacka, 1988, p.45)

In some ways the public sector provides an opportunity to examine the implications of these potential problems for design of information systems. This kind of staff loss and turn-over, as well as the economizing of managers, coupled with the technological improvements of the "information age"3, has led to an increasing reliance on automated quantitative management information systems (MIS) at the expense of the human qualitative systems.

In order to understand what can be done to address the problems of continuing organizational restructure and the role of information systems, it is important to examine the underlying concepts of the "information age". The two relevant components are the intellectual skill-base and the learning organization which theoretically enhance the quality of the organization's database. Lessem (1990) sees the intellectual skill-base as an organization's most precious resource. It is the intellectual skill which is relevant to, and enhances the qualities of "wholeness", "interdependency" and "integration" of information in an organization. The second major component of the information age will be the "learning organization" (deGeus, 1988; Senge, 1990); the organization's ability to learn faster than its competitors. Zuboff (1988) considers that learning and integration constitute the two most vital priorities in such a work-place. Consequently it is the knowledge that people have, and how they use the database of information available to them, which are the keys to a learning organization and yet in "down-sizing" it is a diminishing resource with which information managers must cope.

The key to these "soft systems" (Checkland, 1981) problems associated with organizational restructuring are related to the concept of "total corporate memory". This concept is implicit within the analogies used to explain effective organizations, i.e., "cybernetics" (Wiener 1961).

\section{Components of corporate memory}

Walsh and Ungston (1991) have reviewed the literature on what has been called "organizational memory", in an attempt to provide a more coherent theory of the storage of information about an organization's history which can be brought to bear on decision making in the present and future. They recognise the concern about anthropomorphism in the reification of the analogy of the organization (and its memory) with the human brain or mind. Nevertheless they attempt to investigate the locus of storage of the information in organizational memory; to examine how information is acquired, stored and retrieved from memory, and the manner in which the recalled information is able to be used in decision making and performance of the organization. Also recently Tsoukas (1991) has addressed the development of the organism analogy, and the brain analogy by continuing the work of Beer (1972).

The present paper is less ambitious than that by Walsh and Ungson (1991). Here the authors attempt only to define the various components of data which could be the basis for information storage and retrieval, and to examine the implications of some staffing practices on the potential for retention of that data. In this endeavour we focus on some of the lessons identifiable in the experience of public sector organizations in Australia.

The derivation of organizational memory is uncertain, but the origin of the concept of information storage in systems has been implicit in systems theory since Norbert Wiener's (c. 1948, see 1961) exposition of cybernetics, defined as the science of communication and control in the animal and the machine. The first part of this definition has to do with the role of information in regulatory systems. The second part to the existence of laws or principles of control that apply to complex learning systems. One aspect of an information system that this concept of cybernetics implies is the concept of memory, or storage, of the information, in order to regulate or control the system and to enable it to learn (Simon, 1976; Wiener, 1961).

Herbert Simon (c. 1945, see 1976) was among the first to specifically refer to memory as a relevant factor in administrative decision making. In the case of corporations we refer to this as "corporate memory". While "corporate memory" has not been satisfactorily identified or investigated in the

3. Also called the post-industrialist society: A shift to a more complex information and communication environment with a shift away from goods production to information based services (Bell, 1973; Lessern, 1990; Masuda, 1980). 
literature, in this paper we define it as being a function of data (both hard and soft) of the corporation as well as the employees of that corporation, which can be expressed as follows:

$$
\begin{aligned}
& C M=f\left(C_{h}, C_{S}, P_{h}, P_{S}\right) \text {, where: } \\
& C M=\text { corporate memory, while: } \\
& C_{h}=\text { Corporate hard system data, i.e., transactional data (e.g., in the accounting } \\
& \text { information systems) and electronically encoded textual data, stored centrally as } \\
& \text { well as distributed through the various network and system hardware; } \\
& C_{S}=\text { Corporate soft system data, which include: } \\
& \qquad \begin{array}{l}
* \\
\text { knowledge surrounding the hard data; } \\
\text { about the organization by the individuals comprising the } \\
\text { organization); }
\end{array}
\end{aligned}
$$

$P_{h}=$ personal hard copy data, i.e., individual personal records of the personnel (gained by virtue of their position or idiosynchratically) stored in hard copy, usually printed or written on paper (e.g., notes in their diaries); $P_{S}=$ personal soft data, i.e., the implicit meaning and individuals' personal views
or recollections stored in their own mind's memory.

The distinction between the corporate and personal concepts were coined to expose the underestimation of the information available which has potential value for the organization. Other authors have referred to similar aspects of the holistic meaning of the contextual aspects of the system by the term "Weltanschauung", literally world view (e.g., Checkland, 1981). However, it has not been common to clarify the sense of corporate memory per se, nor its components.

To appreciate the significance of the problem is it useful to review (in the following sections) some of the organizational issues which have surfaced in the public sector and private sector since the 1980 's.

\section{Research on the "human factor" in organizational restructuring}

Broadly speaking corporate mergers, acquisitions and down-sizing can be described as organizational re-structuring. There is much research work in the difficult, commercially competitive and confidential fields of organizational structure and design (see Mintzberg, 1989) organizational change (see Argyris, 1985; Argyris, 1990) and organizational culture or climate (see Rousseau, 1988). However, there has been little research on the effects of corporate acquisitions, mergers and downsizing on corporate memory and management information systems.

One major research program on the conditions for successful corporate acquisitions by the London Business School (see Hunt, 1988) has shed some light on part of the problem. Professor John Hunt and his team conducted longitudinal studies, including interviews and quantitative information from the buyers and sellers about the whole acquisition process involving 40 British firms. They found that the four most frequently identified factors which tended to affect difficult or failed post-acquisition implementation were (in order of decreasing frequency) the personnel systems and practices (such as differences in pay and conditions), the clash of management styles and the organizational cultures (e.g., differences in the values and belief systems), the apparent risk aversion of the seller's managers (according to the buyer's view they did not accept the challenge presented to them by their new owners). The fourth problem area is the most relevant here, as the researchers put it:

"the Excessive Demands for Information from the buyer's head office. ... The seller has the information and the buyer needs it. Information is the only source of power the seller's managers have in a decidedly unequal distribution of power. Whether the demands were excessive or not is less important than the fact that in over one third of our total sample the sellers were convinced demands were excessive and were irritated by them." (Hunt, 1988, p. 10, emphasis in original) 
It is the organizational power pertaining to the manager's knowledge and access to information which is of major concern in this paper and the research being undertaken. The combination of the managers' knowledge and the complete organizational data is seen as a form of intellectual technology. This is different from the research focused on managers' needs for information (cf McFarlane, 1984; Mintzberg, 1979, 1989). The present research pertains to the information the managers already have gained through their experience, and which is capable of being lost on downsizing. It is hypothesised that the organization needs such $P_{S}$ as well as $P_{h}$ information for its continuity of effectiveness. Thus far research on organizational memory and research on the information needs of managers have neglected these personal information storage issues and focused on the $C_{h}$ and $C_{s}$ information systems (especially that held by computers). Certainly, there is little evidence available about what the system designers in the organization have done or should do in addressing the implications of senior staff turm-over for the information needs of organizations.

\section{INFORMATION: A KEY TO ORGANIZATIONAL EFFECTIVENESS AND COMPETITIVENESS}

Information is a generally accepted variable of organizational effectiveness and is seen as one of the parts of a process that leads to the competitiveness of an organization. Pettigrew (1973) points out that strategically relevant information is required for any effective influence attempt. The development of information that is relevant to the situation requires analysis and insight which in turn implies that all relevant data is available at the time. Competitive advantage is seen to derive from the organization's ability to retrieve and use organizational information, which in turn leads to decision making which provides customers with services or products in a manner superior to the organization's competitors (e.g., see Porter, \& Millar, 1985; McFarlane, 1984). This competitive advantage leads to superior performance by that organization.

A problem inherent in the design and implementation of information systems is prediction of usage. This depends on whether there exists a model of all of the relevant actions which is sufficiently complete with respect to the later use of data produced from that model for decision making. However, as authors such as Alter (1980) have pointed out, there is a difference between the relatively "poor" performance of information systems, which are generally described as complex, and the relatively "good" performance of simple data processing systems. This difference is known as the management information systems gap. Such a gap commonly exists, for example, between the transactional systems and the decision support systems.

\section{Information has Value}

A concept which economists use to measure an opportunity lost is the "opportunity cost" of that opportunity. Without minimising the work done in this area, it is clear that a gap in a management information system represents an opportunity cost. An emerging area of research on this topic is called "information economics". This area of thought argues that business performance is the measure of value for the enterprise and its management, and for the information system and its staff (Parker \& Benson, 1988, p. 8).

While the simplistic elemental system (consisting of a planning, an action, an output, and a feedback loop as fundamental units) provides the means for controlling an organization and is the model for giving the organization a competitive advantage which will create value, it is the flow of information which provides the coherence and meaning to that process. However, information is the conversion of data by a human which gives meaning to the transformation process, i.e., Weltanschauung (Checkland, 1981, p.215).

As Mintzberg (1978, pp. 49-50 emphasis in original) put it so well:

"most work cannot get done without some informal communication. ... At the managerial levels, study after study shows that managers of all kinds favour the verbal channels of the informal system over the documents of the formal ... and they spend almost as much time communicating outside the formal chain as inside it. ... The soft information, intangible and speculative, is simply ignored in the formal MIS despite clear evidence that managers depend on such information. ... The result is that managers bypass the MIS to get much of their own information. 
They build their own networks of informal contacts, which constitute their real information and intelligence systems."

Consequently, managers build their own personal databases which are maintained and controlled by them in both hard $\left(P_{h}\right)$ and soft $\left(P_{s}\right)$ form to enhance organizational data which is stored in hard $\left(C_{h}\right)$ form in the computer and in soft form in the organisational culture $\left(C_{S}\right)$ and networks $\left(C_{S}\right)$. It is this form of "added value" or "opportunity cost" which current information systems tend to ignore as if this information has no value.

\section{The Human Factor in Organizational Memory}

Data for information systems are extracted from two separate domains or spheres. That is the internally developed data of the organization which is collected from its own knowledge and the data that is resident in the domain outside the organization (e.g., see Mintzberg, 1979; Kirzner, 1979; Porter \& Miller, 1985). The ability of an organization to use this data is dependent upon its information systems which track both domains of data and the storage facilities of the organization which hold the data. However, when one reads the information analysis and design literature there is rarely (if ever) any discussion of how to gather, store, or update data of the external variety or how that data should be integrated or interfaced with internally generated data. Clearly, with a body of knowledge available and generally accepted methods of planning which include external data, organizations must gather, store and update this data in order for it to be used in information processing. If the computer systems are not the "memory" of the organization then the logical storage of such data lies in physical hardcopy storage and its access systems are totally reliant upon human memory banks (i.e., $C_{S}$ and $P_{S}$ data).

Further, data which is non-existent in the formal computerised information system (either through oversight or poor design) must also be stored in, and also relies upon, human memory and hardcopy physical storage banks before it can be updated or retrieved into the management information system, in order to provide support for decision making. Two aspects are noticeable with respect to data which eludes capture into the formal computerised information system. The first aspect is that of design error and the second a more subtle form of aggregated information loss due to the nature and design of computer systems. These errors and losses are considered below in turn.

In the first instance, data collection systems are limited by the designer's ability to forecast currently unknown requirements or by inability to correctly interpret the current user requirements. For example, take a University which had a new system designed for managing student enrollments. Then the Department of Employment Education and Training changed its requirements and the University was amalgamated with a college. Both changes were not anticipated at the time the design tender was let and both have a major impact on MIS - as well as the "soft systems" issues like incompatible corporate cultures.

In the second situation the computers ability to store data is limited by the designer's tools in the form of limited syntax in computer languages and the disaggregation of data into machine readable code. In both the limited syntax and the disaggregation there is the potential for information loss through simplification.

In both design errors and aggregation loss the organization depends upon the "user workaround" to interpret or modify the data through utilisation. These "user workaround" practices are human dependent, hence, it is the human minds of selected users which substitute for the organizational memory.

\section{Human Aspects of Information Fragmentation}

Butler et al (1981) propose that there is a connection between fragmentation of information, and the ever changing areas of market available for opportunity exploitation, and the organization's level of success with these opportunities. They argue that the collection, processing and assessment of information is a matter of maintenance of human resources as the area of human resource management is in the best position to gauge the degree of variance in the organization's perceptions. While one could argue that it is data which are collected and processed, not information, there is an intuitive and observational nicety about the relationship between perceptions and an organization's market opportunities (see Kirzner, 1979). 
The solution to information fragmentation proposed by Butler et al (1981) is to recognise the role that humans play in the initiation, facilitation and enhancement of intended strategies. The consequence for organizational data is that if the system design does not accommodate the storage of data from these positions, then data will be stored under personal control and maybe even stored within the individual $\left(P_{s}\right)$ rather than in some form of hard copy $\left(P_{h}\right.$ or $\left.C_{h}\right)$.

\section{CORPORATE MEMORY LOSS IN THE PUBLIC SECTOR}

A number of commentators on "public sector reform" (e.g., Winston, 1991, 1992) have pointed out that the turn-over of staff and the many changes of policy in government, have combined to create a myopia of the effected organizations; they are often unable to detect when they are reinventing the wheel or falling in the same pits as their predecessors. They have become like the punch-drunk boxer, whose continual minor brain damage (from external pounding and internal haemorrhaging of key personnel) has rendered them unable to realize their own inappropriate behaviour, or incapable of remembering enough of their mistakes to learn from them.

As in the private sector, public sector organizations have a duty to meet the needs of their shareholders, and clients, i.e., the tax payers, the general community. It seems reasonable to draw the parallel to include the need for the public sector to develop "learning organizations" (Argyris, 1990; Garratt, 1987; Senge, 1990) to continually assess its delivery towards those needs. Indeed, one of the most important reviews of the public sector in Australia, Chaired by H.C. Coombs, identified organizational improvement as a vital part of public sector administration (Royal Commission on Australian Government Administration, 1976).

\section{A Public Service Restructured}

In the public sector case study being researched, a human service organization was drastically restructured by the Minister, leading first to a large proportion of staff lost through redundancy and then an expansion in the new direction. Both of these moves caused drastic effects on the corporate memory. An example, of how this affected the inefficiency was that the efforts to establish a quality assurance and programme evaluation training program were cut short due to most of the key staff leaving and the system developed to monitor the clients' progress in their program was also disrupted and then later was reinvented by different people with apparently little or no increase in productivity nor increased satisfaction of the staff.

\section{MIS Design Issues Raised}

From the experience of the case studies of public sector organizations being examined it seems that there arise at least three potential system design limitations which take on significance in the downsizing and restructuring of organizations, viz.:

* neglect of the attrition of 'personnel memory' $\left(P_{h}\right.$ and $P_{S}$ data) resulting from the dislocation of staff;

* a focus on managers' needs in the organizational diagnosis and MS design at the expense of the needs of the workers at the client or market interface;

and

* a lag between when the system designers conduct their organizational diagnosis and obtain the organizational information needs, to when the design is fully implemented and the errors become noticeable, the degree of lag can be exacerbated by prevailing conditions of (internal and external) environmental uncertainty (and organizational cultural factors), which are the circumstances that require the most appropriate strategic response of the organization and its managers, and when they are most likely to need an up-to-date MIS. If this lag is exacerbated by internal confusion and resulting staff turn-over, there is a risk that the original goals of the MIS may mis-match the needs of the staff replacing them, as the new comers may not have access to the same degree of inside knowledge or corporate memory. 


\section{IMPLICATIONS AND CONCLUSIONS}

In attempting to rectify some of these problems it seems that the analysts and designers of management information systems need to consider the following points for the benefit of their audience:

1. Exit interviews. The organization's Personnel Manager should conduct exit interviews, or in their absence they should be taken up by the managers responsible for the management information systems. Only by interviewing the staff who are leaving will there be an opportunity to learn what they are taking with them, not simply in physical, hard copy form (taken or destroyed as superfluous by the exiting employee), but also in that ex-employees "implicit" memory of the organization.

This also raises the need for research into the processes of obtaining such information, and research regarding the extent of knowledge that leaves the corporate memory when staff have departed.

2. Disposal of personal records. When staff leave in large numbers it is probably too late to consider the need for a systematic review of the personal records which may have been disposed of, with the consequent loss of data. Managers responsible for management information systems need to consider the strategic significance of the confidential information and crucial implicit memory data which could be lost during the down-sizing or re-structuring. Formulating a policy (including intellectual property agreements with staff) on corporate memory review and retention as part of the restructuring or merger etc. could be a contribution to the strategic planning.

3. Limitations of new technology. The expectation that the installation of a state-of-the-art mass optical storage system will solve the corporate memory problems is naive. The point of this paper is that the personnel themselves are the vital memory resource. It is their experience and know-how which even the "expert systems" are not able to entirely replace. Even if the new systems could store all the relevant information, the goodwill of the retrenched staff would be a crucial factor in accessing the departing information.

4. Strategic significance of externally sourced data. Individuals who deal with the extemal environment acquire and generate valuable data on the strategic environment. The data gathered externally by these personnel is not usually entered into management information systems, which are usually internally - or control-oriented. Organizations need to consider the literature on strategic external environmental scanning and establish conduits for obtaining and storing such external data. This also puts an emphasis back on the information needs of crucial personnel with strategic roles to play in the organization's planning and information systems. The other side of the coin about external competitiveness is that individuals who leave the organization are available to be recruited by the organization's competitors. The obvious significance of this goes beyond the corporate memory as it is damaging externally as well as internally.

5. On-going consultancy. Some of these problems can be lessened or avoided by retaining the exiting personnel on a consultancy basis to be recalled and paid when doubts arise about information needed or solutions to old problems. Redeploying staff as contractors is sometimes feasible in the public sector as well as the private sector. Of course, this again reflects on the mode and rationale for dismissal and the degree of good will, and confidentiality involved.

6. Appropriate control aspects. It should be possible to redesign or accommodate the personnel aspects of corporate memory in the management information systems. Of course there are control issues that the designers need to address with respect to this new form of data (as to its update, storage and access). These control issues pertain especially to the strategic types of data (e.g., information about competitors), as well as the data perceived as confidential or personal (e.g., personal opinion). 
7. Collaboration in Information Economics research. There are no simple solutions for the problems found at the interface between management, computing, personnel psychology, and information economics. However, there is a need for managers in the information systems area to liaise with researchers in emerging disciplines in order for the practical edge of application to adopt concepts which are relevant or to exert influence over the agenda of researchers where appropriate.

\section{FURTHER RESEARCH}

The lack of relevant Australian case studies concerning the effects of organizational change on management information systems is a serious deficiency, for academics and practitioners. The difficulty in obtaining access to the qualitative, personal, confidential data, and other pertinent information, is a severe stumbling block to research in this field. The present paper has briefly mentioned two case studies, which are interesting in their introduction to this topic, but greatly in need of elaboration, replication and extension.

There are also logistical difficulties of obtaining information from staff who have now left as they are either uncontactable, unwilling or who themselves are not aware of the information that was relevant. Information would have been destroyed in the hard copy form $\left(P_{h}\right)$, or unrecognised and/or forgotten in the soft form $\left(P_{S}\right.$ andlor $\left.C_{S}\right)$. There is a need for research on such practicalities if the anecdotal evidence of gaps in knowledge or missing information, such as was found in the organizations studied, are to be more precisely investigated.

\section{REFERENCES}

Alter, S.L. (1980) Decision Support Systems: Current Practices and Continuing Challenges. New York: Addison-Wesley.

Argyris, C. (1990) Overcoming organizational defences: Facilitating organizational learning. Boston: Allyn and Bacon.

Beer, S. (1972) The Brain of the Firm: The managerial cybernetics of organization. London: Allen Lane.

Bell, D. (1973) The Coming of Post-Industrialist Society. New York: Basic Books.

Butler, J. Ferris, G \& Napier,N. (1981) Strategy and Human Resources Management. Ohio, USA: South Western Publishing Co.

Cartwright, S. \& Cooper, C.L. (1990) "The impact of mergers and acquisitions on people at work: Existing research and issues." British Journal of Management, Vol. 1, pp. 65- 76.

Cartwright, S. \& Cooper, C.L. (1993) "The psychological impact of merger and acquisition on the individual: A study of Building Society Managers." Human Relations, Vol. 46, No. 3, pp. 327. 347.

Checkland, P. (1981) Systems Thinking Systems Practice. London: Wiley.

Colebatch, T. (1993) "Governments big job shedders" The Age, 29th April, p. 17.

de Geus, A. (1988) "Planning as learning", Havard Business Review, March/April, pp. $70-74$.

Fayol, H. (1916) General and Industrial Management. (transl. from french) London: Pitman, 1949.

Garratt, B. (1987) The learning organization. London: Fontana/Collins.

Jacka, H. (1988) "The Personnel Dimension - Managing Redeployment". Canberra Bulletin of Public Administration, May, Vol 54, pp. 45 - 50.

Kirzner, I. (1979) Perception, Opportunity and Profit. Chicago: University of Chicago.

Lessem, R. (1990) "Introduction" to Y. Masuda, Managing in the Information Society: Releasing synergy Japanese style. Oxford, U.K., Basil Blackwell, pp. i - xxv.

Marks, M.L. \& Mirvis, P.H. (1992) "Rebuilding after the merger: Dealing with `survivor sickness"'. Organizational Dynamics, Autumn, pp. $18-32$.

Marsh, P.(1986) "Are profits the prize of the prey or the predator?" Mergers and Acquisitions, May, Vol. IV -VI,

Masuda, Y. (1980) The Information Society as Post-Industrialist Society. Institute for the Information Society, Tokyo.

McFarlane F. (1984) "Information Technology Changes the Way you Compete" Harvard Business Review, May/June.

Mintzberg, H. (1979) The Structuring of Organizations: A synthesis of the research. Englewod Cliffs, New Jersey: Prentice-Hall. 
Mintzberg, H. (1989) Mintzberg on Management: Inside our strange world of organizations.

N.Y.: Free Press.

Parker M, Benson R, (1988) Information Economics, Englewood Cliffs New Jersey: Prentice Hall.

Pettigrew, A.M. (1973) The Politics of Organizational Decision-Making. London: Tavistock.

Porter, M. \& Millar, V., (1985) "How information gives you a competitive advantage" Harvard

Business Review, Vol. 4, July/Aug, pp 149-160.

Puxty, A.G. (1986) Organization and Management: An Accountant's perspective. London: Pitman.

Review of Commonwealth Administration, (1983) Report, Canberra: Australian Government Publishing Service.

Rousseau, D. (1988) "The construction of climate in organizational research", In Cooper, C.L. \&

Robertson, I. (eds) International Review of Industrial and Organizational Psychology 1988. Chichester: Wiley., pp. 139-158.

Royal Commission on Australian Government Administration (1976) Report. Canberra: Australian Government Publishing Service.

Samper, J.P. (1989) "Changing face of the global corporation: Reflections on the fabled phoenix" Proceedings of the World Management Congress, New York: World Management Council September 22.

Senge, P.M. (1990) The fifth discipline: The art and practice of the learning organization. New York: Doubleday.

Simon, H.A. (1976) Administrative Behaviour: A Study of Decision-making Processing Administrative Organization, third ed. New York: Free Press.

Tsoukas, H. (1991) "The missing link: A transformational view of metaphors in organizational science." Academy of Management Review, Vol. 16, July, pp. 566- 585.

Walsh, J. P. \& Ungson, G.R. (1991) "Organizational memory" Academy of Management Review, vol. 16 , no. 1 , pp. 57 - 91 .

Wiener, N. (1961) Cybernetics or Control and Communications in the Animal and the Machine. Second ed., Cambridge, Mass.: M.I.T. Press.

Winston, J. A., (1991) "On-going issues: Performance management - Review paper: Linking evaluation and performance management". Proceedings of the National Evaluation Conference, Adelaide: Australasian Evaluation Society and State Print, pp. 599 - 606.

Winston, J. A. (1992) "Performance indicators for program evaluation: The case against." Unpublished Draft paper presented at the conference on Program Evaluation in the Public Sector. Sydney: IIR Conferences, 6th April.

Zuboff, S. (1988) In the Age of the Smart Machine. London: Heinemann. 